\title{
Relação entre Estratégias de Preços e de Custeio
}

\author{
Relationship Between Prices and Costing Strategies
}

Gabriel Sperandio Milan

Professor e pesquisador da UCS - Universidade de Caxias do Sul - Caxias do Sul - RS - Brasil. E-mail: gsmilan@ucs.br

Deonir De Toni

Professor e pesquisador da UCS - Universidade de Caxias do Sul - Caxias do Sul - RS - Brasil. E-mail: DToni2@ucs.br

Fabiano Larentis

Professor e pesquisador da UCS - Universidade de Caxias do Sul - Caxias do Sul - RS - Brasil. E-mail: flarenti@ucs.br

Alexandre Majola Gava

Consultor Financeiro, Faculdade Cenecista de Bento Gonçalves - Bento Gonçalves - RS - Brasil. E-mail: ale.gava@terra.com.br.

\section{Resumo}

O presente trabalho apresenta uma pesquisa realizada em 84 empresas, localizadas na Serra Gaúcha, abordando os seus processos de formação de preços e de custeio, buscando determinar relações entre as principais variáveis inerentes às áreas de marketing, de finanças e de controladoria. Os resultados iniciais sugerem que parece haver uma relação significativa entre a competitividade percebida no ambiente e a forma como o custeio é tratado pelas empresas, pois parece que mercados mais competitivos exigem o uso de técnicas mais avançadas em relação à aferição dos custos e, como decorrência, na definição das estratégias de precificação. Além disso, o enfoque da formação de preços, suas estratégias, políticas e decisões, baseado no valor percebido pelos clientes e o impacto dos custos neste contexto, e não apenas no enfoque das práticas da concorrência, também, incentivam o uso de técnicas mais apuradas de custeio. Finalmente, foi possível observar que a sofisticação dessas técnicas está relacionada ao porte, ao tempo de mercado das empresas e ao nível de exigência dos mercados atendidos pela organização, influenciando as estratégias de preço.

Palavras-chave: Custeio. Formação de Preços. Estratégia de Preços.

\section{Abstract}

This paper presents a study conducted in 84 companies located in the Serra Gaúcha, addressing the processes of pricing and costing, to determine relationships among major variables related to the areas of marketing and finance and controller. Initial results suggest that there seems to be a significant relationship between perceived competitive environment and how the funding is handled by companies as more competitive markets seem to require the use of more advanced techniques for the measurement of costs and as a consequence, the definition of pricing strategy. Moreover, the approach of pricing, its strategies, policies and decisions, based on customers' perceived value and impact of costs in this context and not just focus on practices based on competition, also encourages the use of better techniques costing. Finally, we observed that the sophistication of these techniques is related to size, time to market of enterprises and the level of demand from markets served by the organization, influencing pricing strategies.

Key words: Costing. Pricing. Pricing Strategy. 


\section{INTRODUÇÃO}

Diante da intensidade competitiva, em que o número de ofertas está aumentando consideravelmente e que entrantes potenciais locais e internacionais estão cada vez mais agressivos, observa-se que o preço representa uma das variáveis fundamentais para a sustentação de uma empresa a curto, médio e longo prazos (NICHELE; MILAN, 2006). Assim, o paradigma do mero repasse dos custos e despesas, somado ao lucro para a formação do preço de venda, necessita ser analisado a partir das novas contingências de mercado. Ou seja, estratégias que buscam uma visão não só de dentro para fora da empresa, mas também de fora para dentro, no sentido de buscar uma análise mais aprofundada do mercado, verificando o que o mercado está disposto a pagar pela oferta das empresas (produto e/ou serviço) ou o que é valor na percepção do consumidor despontam como alternativas para melhorar o desempenho das organizações. (BERNARDI, 1996)

Segundo Ramos, Maya e Bornia (2005), a maneira mais rápida e mais eficaz para que uma empresa maximize seu lucro é começar fixando o preço corretamente. Além disso, o preço tem um impacto muito forte sobre o volume de vendas e a participação de mercado. Sua influência temporal é mais rápida que outros elementos, e pode ser modificada com relativa rapidez. Sendo assim, a forma pela qual as empresas definem seus preços não influencia apenas o comportamento da demanda, mas também o modo como os compradores utilizam o produto e/ou o serviço, podendo impactar positivamente no estabelecimento, na manutenção e na ampliação de relacionamentos duradouros entre as partes, ou seja, entre comprador e vendedor. (GOURVILLE; SOMAN, 2002)

De acordo com Diamantopoulos (2005), melhorias no preço normalmente causam um efeito de três a quatros vezes maior sobre o lucro e sobre a rentabilidade de um negócio do que aumentos proporcionais no volume de vendas. Assim, o preço reflete duas dimensões simultâneas. Primeiro os sacrifícios que o comparador incorre para adquirir a oferta e, segundo, como um sinal de qualidade do produto, sendo fundamental na direção do sucesso ou fracasso de um novo produto e/ou serviço. (DIAMANTOPOULOS, 2005; SIMON, 1992)
Apesar da importância desse tema, o que se observa na literatura de marketing é que há uma carência de estudos relacionados à precificação (CRESSMAN Jr., 1999; DIAMANTOPOULOS, 2005; NICHELE; MILAN, 2006). Para Diamantopoulos (2005), muitos pesquisadores têm se concentrado em modelos de determinação de preços distantes da realidade dos gestores, ou difíceis de implementar, sendo que a participação das empresas em levantamentos empíricos de determinação de preços frequentemente é baixa. Todavia, com o avanço cada vez maior da tecnologia da informação nas empresas, há uma maior possibilidade de adoção de análises mais sofisticadas na determinação dos preços e da implementação de estratégias de preços mais adequadas. (WYNER, 2001)

O que se percebe, além disso, é que enquanto a literatura de marketing e o desenvolvimento de uma orientação para o mercado pressupõem uma visão estratégica voltada para o ambiente externo, muitas das estratégias de preços das organizações estão centradas na própria organização. Em um estudo desenvolvido por Monroe e Cox (2001), foi verificado que $88 \%$ das empresas não utilizam ou não possuem um programa sério de pesquisas de preços antes de definir suas estratégias de precificação. Isso indica que as decisões de preço tendem a ser tomadas sem um entendimento profundo sobre as possíveis reações dos compradores e da resposta dos competidores. Conforme os autores, muitas empresas têm sido lentas em desenvolver uma abordagem proativa na definição das estratégias de preço. Em relação a isso, comenta-se, ainda, que as empresas se restringem mais a decisões táticas $e$ operacionais, ao invés da definição de estratégias em nível corporativo.

É importante ressaltar que diferentes áreas funcionais de uma organização podem focar diferentes objetivos. O departamento financeiro, por um lado, pode estar preocupado somente em obter o máximo de lucro possível, enquanto o departamento de vendas, por outro lado, pode querer obter maior participação de mercado e volume de negócios. Dessa forma, cabe à gestão da empresa buscar uma inter-relação entre a busca de uma maior participação de mercado, volume de receitas, satisfação de clientes, lucro e rentabilidade, estabelecendo, assim, estratégias de formação de preços que contribuem significativamente para um melhor desempenho organizacional. Neste contexto, o 
presente trabalho tem por objetivo analisar o emprego de diferentes estratégias de formação de preços e sua relação com sistemas e ações de custeio junto a empresas dos setores: industrial e de serviços, localizadas na Serra Gaúcha.

\section{Revisão da Literatura}

Em relação à revisão da literatura, para facilitar a compreensão em torno dos temas centrais de discussão, foram abordados o contexto da precificação $e$ as estratégias de preço (precificação), o que é apresentado na sequência.

\subsection{Contexto da Precificação}

Estratégias de precificação são fundamentais ao marketing, visto que elas condicionam o faturamento $e$ refletem a percepção que o consumidor tem a respeito dos produtos e/ou serviços da empresa. Uma estratégia de preços consistente deve avaliar as forças que moldam o mercado, a sensibilidade ao preço por parte dos clientes, as interações com a concorrência e a própria situação interna da empresa (TORRES; MARTINS, 2006). Especificamente sobre a sensibilidade ao preço, é oportuno comentar que, em parte, pode ser entendida pela falta de diferenciação da oferta, repercutindo na decisão de compra do consumidor com base no preço, preferencialmente, o menor possível. (DOLAN; SIMON, 1998)

Vale destacar que cada tipo de oferta apresenta as suas peculiaridades. Alguns produtos e/ou serviços são considerados novos, outros são complementos de linha ou são geradores de caixa, outros estrategicamente servem como elemento de um "pacote de produtos e/ ou serviços" ou funcionam como impulsionadores de vendas, pois auxiliam na venda de outros itens do mix. Isso é plausível até porque o lucro pode ser explicado como resultante de mix de produtos e/ou serviços com diferentes margens de lucro e rentabilidade e diferentes níveis de giro nas vendas e volume de negócios. (McDONALD, 2004)

Por isso, a formação e a definição de preços somente com base no custo acrescido do lucro é uma visão míope, que não leva em consideração a relação existente entre a empresa e o seu mercado de atua- ção. Maximizar o lucro nem sempre é o principal ou o único objetivo do processo de formação e definição dos preços de venda para as empresas. Portanto, traçar os objetivos diretivos, e estabelecer as estratégias e as políticas de preço são elementos fundamentais para elevar a performance do negócio ao longo do tempo. (DOLAN; SIMON, 1998; NAGLE; HOLDEN, 2003; KOTLER; KELLER, 2006; NICHELE; MILAN, 2006)

\subsection{Estratégias de Preço (Precificação)}

A estratégia de preço é o meio ou a forma como os objetivos de preço podem ser alcançados. Com isso, observa-se que não há estratégias predeterminadas. $\mathrm{Na}$ verdade, muitos gestores se equivocam ao tentar implementar modelos que demonstraram eficiência em outras empresas, setores ou em outras situações de mercado. A estratégia de preços acertada, portanto, depende da correta aferição e ponderação dos custos, do valor percebido da oferta por parte dos compradores e da atuação dos concorrentes. (TORRES; MARTINS, 2006)

Por conseguinte, os fatores determinantes da escolha do preço são baseados em condições internas e externas à organização. Com um volume cada vez maior de informações, e informações mais consistentes, o preço pode ser baseado na natureza e no potencial de relacionamento com o cliente, e não somente nos custos inerentes à oferta. Para implementar uma estratégia de preços dinâmica, é importante estimar a elasticidade sobre as várias condições de mercado. Isso implica em compreender as respostas dos clientes para diferentes ocasiões de compra. Por exemplo, a compra por impulso versus a compra planejada; a compra no inverno versus a compra no verão (sazonalidade); a compra de presentes versus a compra para uso pessoal. Além disso, uma boa estratégia de preço envolve um entendimento do ambiente competitivo e do que pode gerar de valor para o cliente. (WYNER, 2001)

Geralmente, costuma-se tratar a precificação como a estratégia mais simples dentro do composto de marketing. Resultados provenientes de estudos realizados por Simon (1992), Souza et al. (2005) e Souza (2006) indicam que muitas empresas determinam seus preços com base na intuição, em paradigmas vigentes e na experiência de mercado dos gestores. Não há, em muitos casos, a preocupação com um sistema de 
informações que dê suporte, em um nível adequado, ao processo de tomada de decisões, seja na estimação dos custos, seja na formação dos preços. A capacidade de coletar, armazenar, processar e disponibilizar informações oriundas dos ambientes, interno e externo, constitui um recurso fundamental no que se refere ao suporte às decisões de preço de maneira confiável $e$ rentável. (KOTLER; KELLER, 2006)

Sob a perspectiva de finanças e de controladoria, há pesquisas, aplicadas no Brasil, direcionadas ao processo de precificação. Para Machado et al. (2006), o processo de formação de preços em hotéis, localizados em João Pessoa (PA), é fortemente baseado nos custos totais da operação. Em pesquisa aplicada por Nascimento Neto e Miranda (2003), em 81 empresas, os resultados demonstram que o tradicional custeio por absorção, que apropria custos fixos e variáveis aos produtos ou serviços, segue como o principal método de custeio em nosso país, independentemente do grau de complexidade dos custos nestas empresas.

Outros trabalhos têm enfatizado que métodos mais recentes, tais como o custeio ABC (Activity-Based Costing) tem tido um espaço de penetração não muito significativo, como reportam Vieira e Robles Júnior (2002) em sua pesquisa com 75 empresas do setor de autopeças no estado de São Paulo. Entretanto, um número significativo de empresas está desistindo de utilizar o $\mathrm{ABC}$ após a sua implantação devido à dificuldade de manutenção do sistema. No geral, os estudos apontam para um uso bastante conservador dos métodos de custeio e de formação de preços no país sob o ponto de vista financeiro e de controladoria.

Por outro lado, considerando que o preço tem um efeito significativo sobre a participação de mercado, o volume de negócios e a lucratividade e a rentabilidade das empresas, falhas e problemas na formação de preços podem causar verdadeiros desastres organizacionais. Estratégias de redução de preços, por exemplo, nem sempre são benéficas para a empresa, mesmo que, em tese, dependendo do tipo da oferta, poderiam estimular o aumento no volume de vendas. Mesmo tendo como lógica a manutenção da lucratividade com o aumento do volume de vendas, os clientes atuais possuem uma capacidade limitada de compra ou de consumo, sem falar que os concorrentes poderão fazer retaliações, reduzindo, também, seus preços, o que poderia acarretar na competição predatória no setor e em uma guerra de preços (GUILTINAN; GUNDLACH, 1996; RAO; BERGEN; DAVIS, 2000; HEIL; HELSEN, 2001; DIAMANTOPOULOS, 2005). Portanto, a definição de preços é uma atividade complexa e exige, além de um bom entendimento da estrutura interna da empresa, um bom conhecimento do mercado e das diversas variáveis que o compõem e suas interfaces.

Noble e Gruca (1999) buscam entender os fatores que determinam quais estratégias podem ser adotadas para a determinação dos preços. Esses autores apresentam quatro categorias de estratégias de preços: (i) para novos produtos e/ou serviços; (ii) preços competitivos; (iii) preços por linhas de produtos e/ou serviços; e (iv) preços baseados em custos. Em contrapartida, em uma crítica a essa proposição, Cressman Jr. (1999) argumenta que os pesquisadores de marketing devem reexaminar seus trabalhos no sentido de assegurar que estão empregando uma prática de preços baseada no valor percebido pelos clientes. Logicamente, os custos são importantes para a definição da estratégia de preços, principalmente na avaliação do impacto do lucro nas ações do preço, mas os custos, isoladamente, não permitem identificar a correta estratégia de preço. $\mathrm{O}$ autor reitera que nenhuma das quatro categorias de estratégia de preços proposta por Noble e Gruca (1999) inclui explicitamente o preço baseado na entrega de valor ao cliente.

Há, então, uma desconexão entre a estratégia de preços e a entrega de valor para os clientes, o que pode afetar profundamente os resultados atinentes das estratégias de marketing. Outra observação do autor é que o preço baseado no valor deve ser explicitamente incluído na literatura de orientação para o mercado. As práticas de preço são os meios pelos quais os gestores podem "colher" o valor gerado para os clientes a partir das estratégias implementadas. Para tanto, o primeiro passo para a compreensão do papel do valor para o cliente é a segmentação de mercado, sendo que, para posicionar um produto e/ou um serviço corretamente em um segmento ou nicho de mercado, deve-se começar pelo entendimento sobre quais são os benefícios que cada grupo de cliente-alvo deseja (KRISHNAMURTHI, 1999). A precificação, como decorrência disso, também deveria estar fundamentada na prática da filosofia do marketing, ou seja, entender e atender os clientes. (KOTLER; KELLER, 2006) 
Nesse sentido, o Quadro 1 apresenta, além das quatro categorias de estratégia de preços propostas por Nobel e Gruca (1999), outras estratégias que consideram o ajuste dos preços com base na oferta de valor superior aos clientes, contemplando o entendimento defendido por Cressman Jr. (1999). (BERNARDI, 1996; CRESSMAN Jr., 1999; MONROE; COX, 2001; URBANY, 2001; COGAN, 2002; DIAMANTOPOULOS, 2005; KOTLER; KELLER, 2006)

\begin{tabular}{|c|c|c|}
\hline ESTRATÉGIAS & Descrição & Preço \\
\hline \multicolumn{3}{|c|}{ Novos Produtos } \\
\hline Desnatamento & $\begin{array}{l}\text { Fixação de preço alto no início da vida do produto, reduzindo-se o preço à } \\
\text { medida que o volume de venda diminui. }\end{array}$ & Alto \\
\hline Preço de penetração & $\begin{array}{l}\text { Preços baixos para acelerar a adoção do produto e estimular o crescimento e as } \\
\text { vendas em mercados ainda não atendidos. }\end{array}$ & Baixo \\
\hline Preço de curva de experiência & $\begin{array}{l}\text { Fixação de preço baixo para construir volume e redução de custo através do } \\
\text { acumulo de experiência. }\end{array}$ & Baixo \\
\hline \multicolumn{3}{|c|}{ Preços Competitivos } \\
\hline Líder de preços & $\begin{array}{l}\text { A empresa é líder de preço e determina o nível de preço do setor. Geralmente a } \\
\text { empresa inicia com um preço e espera que outras empresas a sigam. }\end{array}$ & Alto \\
\hline Igualar a estratégia dos competidores & A empresa segue o preço da média do mercado ou do líder. & Igual \\
\hline $\begin{array}{l}\text { Preço mais baixo que dos } \\
\text { competidores }\end{array}$ & A empresa fixa os preços a níveis inferiores aos do mercado. & Baixo \\
\hline \multicolumn{3}{|c|}{ Preços por Linhas de Produto } \\
\hline Produtos complementares & $\begin{array}{l}\text { O produto central é fixado com preço baixo, porém os complementares, tais } \\
\text { como acessórios, serviços, etc., são fixados com preços maiores. }\end{array}$ & Baixo \\
\hline Preço por pacote & $\begin{array}{l}\text { É estabelecido um preço para o conjunto de produtos, Geralmente é dado } \\
\text { um atrativo maior ao cliente no pacote do que a compra destes produtos } \\
\text { individualmente. }\end{array}$ & Baixo \\
\hline Preço com valor para o cliente & $\begin{array}{l}\text { São oferecidas ao cliente uma versão do produto com características inferiores a } \\
\text { outras versões. }\end{array}$ & Baixo \\
\hline \multicolumn{3}{|c|}{ Preço Baseado em Custos } \\
\hline Custo mais lucro & O preço é estabelecido com base no custo e no percentual de lucro. & - \\
\hline \multicolumn{3}{|c|}{ Estratégia de Preço e Imagem } \\
\hline Preço de referência & $\begin{array}{l}\text { Formação de preço de forma comparativa com base em preços que o } \\
\text { consumidor já tem em mente. }\end{array}$ & \\
\hline Preços prestígio & $\begin{array}{l}\text { Ocorre quando os consumidores observam o preço de determinado produto } \\
\text { como indicador de alta qualidade. }\end{array}$ & Alto \\
\hline \multicolumn{3}{|c|}{ OUTRAS ESTRATÉGIAS } \\
\hline \multirow{2}{*}{$\begin{array}{l}\text { Estratégia com base no valor superior } \\
\text { para o cliente }\end{array}$} & $\begin{array}{l}\text { Fixação de preços mais baixos que os competidores, mas com benefícios } \\
\text { equivalentes. }\end{array}$ & Baixo \\
\hline & $\begin{array}{l}\text { Preços mais altos que os concorrentes por apresentarem benefícios exclusivos ou } \\
\text { superiores. }\end{array}$ & \\
\hline Estratégia Premium & Preços altos em função da qualidade superior. & Alto \\
\hline $\begin{array}{l}\text { Descriminação ou customização de } \\
\text { preço }\end{array}$ & Preços diferenciados de acordo com as características do cliente & \\
\hline
\end{tabular}

Quadro 1: Estratégias de formação de preços

Fonte: Adaptado de Noble e Gruca (1999), Bernardi (1996), Cressamn Jr. (1999), Monroe e Cox (2001), Urbany (2001), Cogan (2002), Diamantopoulos (2005) e Kotler e Keller (2006) 


\section{Método de Pesquisa}

Foi realizado um estudo de natureza quantitativa e de corte transversal, após a estruturação e finalização do questionário mediante pré-teste (HAIR Jr.; BUSH; ORTINAU, 2000; MALHOTRA, 2006). O processo de coleta de dados ocorreu junto a empresários e executivos conhecedores das práticas de precificação e de custeio de suas organizações.

O questionário de pesquisa se divide em duas partes. A primeira parte avaliando a precificação e novos produtos; e a segunda parte, avaliando os métodos $e$ ações de custeio. Na primeira parte foram utilizadas as escalas de Noble e Gruca (1999), para estratégias de precificação, de Urdan e Osaku (2005), para os fatores de definição de preços, e as escalas de Ingenbleek et al. (2003), para a avaliação da concorrência, do setor, dos objetivos para novos produtos e do desempenho de produtos. Avaliou-se, também, o grau de inovação existente, a partir das adaptações efetuadas nos produtos. Gerou-se, assim, um instrumento de coleta de dados com 74 variáveis relacionadas à precificação e a novos produtos (Anexo A). A parte do questionário que se refere aos custos se baseou no exame da literatura da área, focando-se em pesquisas empíricas realizadas no Brasil. (MACHADO et al., 2006; SOUZA, 2006)

Os questionários foram enviados por e-mail ou entregues pessoalmente para o autopreenchimento dos respondentes potenciais. De um total de 600 questionários enviados ou entregues, foram recebidos 84 questionários válidos, obtendo-se um retorno de $14 \%$. Após a verificação da base de dados e a correção de inconsistências, procederam-se as análises de dados no software estatístico SPSS. Além de estatísticas descritivas, foram efetuadas a Análise Fatorial, para redução do número de variáveis, análises de diferenças de médias (ANOVA) e Análise de Regressão. (HAIR Jr. et al., 1998; JOHNSON; WICKERN, 2002)

\section{Análise e Discussão dos Resultados}

As empresas que responderam ao questionário apresentam, em média, 22 anos de tempo de mercado, e estão localizadas no estado do Rio Grande do Sul. Quanto à natureza econômica das empresas, 77,1\% delas atua no setor industrial, e os restantes $22,9 \%$, no setor de serviços. Além disso, 53,3\% delas apresentam um faturamento anual líquido de até $\mathrm{R} \$ 1,5$ milhão; $57,1 \%$ possuem até 30 funcionários; $44 \%$ mantêm atividades em mercados externos, $50,6 \%$ possuem até seis concorrentes diretos; $53,7 \%$ têm até 35 produtos em comercialização; $61,4 \%$ possuem seus principais produtos com um tempo médio no mercado de até cinco anos; e 45,7\% das empresas lançaram até cinco produtos nos últimos dois anos.

Por outro lado, $48,7 \%$ das empresas utilizam como método de custeio o custo-padrão; $20,5 \%$, o custo por absorção; e 20,5\%, o custeio direto. Em relação à análise CVL (custo-volume-lucro ou ponto de equilíbrio), 30,9\% das empresas não a utilizam; 56,8\% a utilizam e empregam funções lineares; e 12,3\% a utilizam, também, porém, empregando funções não lineares; $26,9 \%$ não estabelecem padrões de custeio $e$ $35,9 \%$ utilizam rateios. Quanto à revisão dos padrões adotados, $29 \%$ das empresas avaliam estes padrões mensalmente; $28 \%$, semestralmente; e $44 \%$ delas, quando necessário.

No que diz respeito à existência ou não de um manual de custeio, $32,5 \%$ das empresas possuem um manual de procedimentos para custeio. Outro aspecto interessante é que $32,9 \%$ das empresas pesquisadas já utilizaram ou utilizam consultoria externa para a implantação de sistemas de custeio; sendo que 42,3\% delas utilizam planilha eletrônica com software para custeio; 17,9\%, sistema específico; e 39,7\%, uma combinação de ambos, ou seja, sistema e planilha eletrônica.

Além disso, para cada um dos blocos que compunham a primeira parte do questionário (fatores para definição dos preços, desempenho do produto, estratégias de precificação, objetivos para novos produtos, concorrência e setor), procedeu-se a Análise Fatorial. Para tanto, foram utilizados o método de componentes principais para extração dos fatores, rotação Varimax e tratamento pairwise dos dados omissos (missings). Cabe ressaltar que o número de respostas omissas nas variáveis intervalares ficou em torno de $5 \%$ em relação às variáveis respondidas. Para a definição do número de fatores, considerou-se como critério aqueles com autovalor acima de um. Ademais, identificou-se, para cada fator, o Alfa de Cronbach, para o teste de confiabilidade. (JOHNSON; WICHERN, 2002; HAIR Jr. el al., 1998) 
No bloco relacionado aos fatores para definição dos preços, composto por 19 variáveis, obteve-se quatro fatores, com uma variância explicada de $65 \%$, teste $\mathrm{KMO}$ e de esfericidade de Bartlett em níveis adequados $(0,60$ e significância ao nível de 0,05) (MALHOTRA, 2006). Praticamente todas as comunalidades ficaram acima de 0,5 (a variável 5 obteve uma comunalidade de 0,45 ). Todas as cargas obtiveram valores acima de 0,5 , com exceção da variável 13 , com 0,49 (JOHNSON; WICHERN, 2002; HAIR Jr. et al., 1998). A Tabela 1 é elucidativa.

Tabela 1: Fatores identificados para a definição de preços

\begin{tabular}{|c|c|c|}
\hline $\begin{array}{l}\text { Fatores Identificados para a } \\
\text { Definição de Preços }\end{array}$ & VARIÁVEIS & $\begin{array}{c}\text { Alfa de } \\
\text { Cronbach }\end{array}$ \\
\hline $\begin{array}{l}\text { F1: Estrutura e competição de } \\
\text { mercado }\end{array}$ & V6 a V13 & 0,884 \\
\hline $\begin{array}{l}\text { F2: Custos e margem de lucro } \\
\text { dos produtos e/ou serviços }\end{array}$ & V14 a V17 & 0,843 \\
\hline $\begin{array}{l}\text { F3: Diferenciais e valor } \\
\text { percebido }\end{array}$ & V1 a V5 & 0,783 \\
\hline F4: Níveis de investimento & V18 a V19 & 0,659 \\
\hline
\end{tabular}

Fonte: Elaborada pelos autores deste artigo

No bloco relacionado ao desempenho de produto (variáveis 20 a 23 do questionário), obteve-se apenas um fator, com uma variância explicada de $62,5 \%$, teste $\mathrm{KMO}$ e de esfericidade de Bartlett em níveis adequados e todas as comunalidades acima de 0,5 . Ademais, todas as cargas fatoriais ficaram acima de 0,5 e um Alfa de Cronbach de 0,789.

No bloco relacionado às estratégias de precificação (variáveis 24 a 40), foram obtidos, após a eliminação das variáveis $29,31,32,34$ e 39, em função das cargas fatoriais baixas (abaixo de 0,4), cinco fatores, correspondendo a $73,2 \%$ da variância explicada. O teste $\mathrm{KMO}$ ficou um pouco abaixo do recomendado $(0,59)$ e o teste de esfericidade de Bartlett em nível adequado. Além disso, foi obtida uma comunalidade próxima a 0,4 e uma carga fatorial de 0,46 (ambas da variável 30). A Tabela 2 apresenta os fatores relacionados às estratégias de precificação $e$ suas respectivas variáveis:
Tabela 2: Fatores relacionados às estratégias de precificação

\begin{tabular}{|c|c|c|}
\hline $\begin{array}{l}\text { Fatores Relacionados Às } \\
\text { EstratéGIas de PrecificaÇão }\end{array}$ & VARIÁvEIS & $\begin{array}{c}\text { Alfa de } \\
\text { Cronbach }\end{array}$ \\
\hline F1: Penetração de mercado & $\begin{array}{l}\text { V26 a V28 } \\
\text { e V30 }\end{array}$ & 0,806 \\
\hline $\begin{array}{l}\text { F2: Produtos mais simples, com } \\
\text { qualidade de nível baixo ou } \\
\text { intermediário }\end{array}$ & V36 a V38 & 0,583 \\
\hline F3: Desnatamento de mercado & V24 a V25 & 0,648 \\
\hline $\begin{array}{l}\text { F4: Uso de pacotes de } \\
\text { produtos e/ou serviços e itens } \\
\text { complementares }\end{array}$ & V35 e V40 & 0,464 \\
\hline F5: Uso de números quebrados & V33 & - \\
\hline
\end{tabular}

Fonte: Elaborada pelos autores deste artigo

No bloco relativo à conquista de objetivos para novos produtos, (variáveis 41 a 43), obteve-se um único fator, com uma variância explicada de 77,5\%, teste $\mathrm{KMO}$ e de esfericidade de Bartlett em níveis adequados e todas as comunalidades acima de 0,5. Por outro lado, todas as cargas fatoriais ficaram acima de 0,5 e obteve-se um Alfa de Cronbach de 0,854. No bloco relacionado à avaliação da empresa em comparação à concorrência (variáveis 44 a 60), foram obtidos, após a eliminação da variável 47, em função da carga fatorial baixa (abaixo de 0,4), seis fatores, correspondendo a 74,1\% da variância explicada, bem como o teste $\mathrm{KMO}$ e de esfericidade de Bartlett em níveis adequados, além de todas as comunalidades e cargas fatoriais acima de 0,5. A Tabela 3 apresenta os fatores relacionados à avaliação da empresa em relação à concorrência e suas respectivas variáveis:

Tabela 3: Fatores relacionados à avaliação da empresa em comparação à concorrência

\begin{tabular}{|c|c|c|}
\hline $\begin{array}{c}\text { FATORES RELACIONADOS À } \\
\text { AvaliaÇão dA EMPRESA EM } \\
\text { COMPARAÇÃo À CoNCOR- } \\
\text { RÊNCIA }\end{array}$ & VARIÁVEIS & $\begin{array}{c}\text { Alfa de } \\
\text { Cronbach }\end{array}$ \\
\hline $\begin{array}{l}\text { F1: Diferenciação, vendas e } \\
\text { rentabilidade }\end{array}$ & $\begin{array}{l}\text { V48, V52 a V53 } \\
\text { e V55 a V56 }\end{array}$ & 0,757 \\
\hline $\begin{array}{l}\text { F2: Vantagens em custos } \\
\text { (economias de escala e } \\
\text { curva de experiência) e } \\
\text { facilidade na detecção de } \\
\text { mudanças nos preços }\end{array}$ & $\begin{array}{l}\text { V44 a V45 e } \\
\text { V54 }\end{array}$ & 0,681 \\
\hline F3: Custos fixos e variáveis & V49 a V50 & 0,865 \\
\hline
\end{tabular}




\begin{tabular}{|c|c|c|}
\hline $\begin{array}{c}\text { FATORES RELACIONAdOS À } \\
\text { AvaliaÇão DA EMPRESA EM } \\
\text { COMPARAÇÃo À CONCOR- } \\
\text { RÊNCIA }\end{array}$ & VARIÁVEIS & $\begin{array}{c}\text { Alfa de } \\
\text { Cronbach }\end{array}$ \\
\hline F4: Mercados e clientes & V46, V51 e V59 & 0,693 \\
\hline $\begin{array}{l}\text { F5: Produtos e/ou } \\
\text { serviços comercializados e } \\
\text { lançamentos }\end{array}$ & V58 e V60 & 0,513 \\
\hline F6: Custos de mudança & V57 & - \\
\hline
\end{tabular}

Fonte: Elaborada pelos autores deste artigo

No último bloco da primeira parte do questionário, o setor de atuação da empresa, (variáveis 61 a 73), foram obtidos, após a eliminação da variável 62 , em função da carga fatorial baixa (abaixo de 0,4), 5 fatores, correspondendo a $74,2 \%$ da variância explicada, assim como o teste $\mathrm{KMO}$, um pouco abaixo do recomendado (0,52), e o de esfericidade de Bartlett, em nível adequado. Todas as comunalidades e cargas fatoriais obtidas ficaram acima de 0,5. A Tabela 4 apresenta os fatores relacionados ao setor de atuação da empresa e suas respectivas variáveis:

Tabela 4: Fatores relacionados ao setor de atuação da empresa

\begin{tabular}{|c|c|c|}
\hline $\begin{array}{c}\text { Fatores Relacionados ao Se- } \\
\text { tor de Atuação da Empresa }\end{array}$ & VARIÁVEIS & $\begin{array}{c}\text { Alfa de } \\
\text { Cronbach }\end{array}$ \\
\hline $\begin{array}{l}\text { F1: Sensibilidade da demanda } \\
\text { e dos clientes ao preço }\end{array}$ & $\begin{array}{l}\text { V64 a V65 } \\
\text { e V70 }\end{array}$ & 0,616 \\
\hline $\begin{array}{l}\text { F2: Custos do setor como um } \\
\text { todo }\end{array}$ & V67 a V68 & 0,860 \\
\hline $\begin{array}{l}\text { F3: Poder de barganha de } \\
\text { clientes e de fornecedores }\end{array}$ & V71 e V72 & 0,735 \\
\hline $\begin{array}{l}\text { F4: Desempenho do setor } \\
\text { como um todo (crescimento, } \\
\text { qualidade de produtos e/ou de } \\
\text { serviços, lucro e rentabilidade) }\end{array}$ & $\begin{array}{l}\text { V61, V66 e } \\
\text { V69 }\end{array}$ & 0,539 \\
\hline $\begin{array}{l}\text { F5: Itens comercializados e } \\
\text { preços praticados }\end{array}$ & V63 e V73 & 0,575 \\
\hline
\end{tabular}

Fonte: Elaborada pelos autores deste artigo

Ao final, foram criadas novas variáveis equivalentes aos fatores a partir das médias das variáveis que integraram cada fator. Assim, com os fatores oriundos da Análise Fatorial, procederam-se as Análises de Variância (ANOVA), para diversas variáveis categóricas. Para as variáveis número de funcionários, ramo de atividades, tempo de mercado da empresa e atividade em mercados externos (todas com duas categorias cada), foram criadas a partir de variáveis de razão e categóricas presentes no instrumento de coleta de dados.

Vale salientar que foi utilizado, como critério, a divisão da amostra em duas partes iguais. Também foram efetuadas ANOVAs para outras variáveis com duas categorias, como existência de manual de procedimentos para custeio, uso de consultoria para implementação do sistema de custeio, número de concorrentes (originada de variável de razão - divisão em partes iguais), número de produtos comercializados (originada de variável de razão - divisão em partes iguais) e lançamento de novos produtos nos últimos dois anos. Os resultados são apresentados nas Tabelas 5 e 6, respectivamente.

Para as variáveis com mais de duas categorias (como método de custeio); com quatro categorias, reavaliação dos padrões utilizados nos métodos de custeio (como percentuais de rateios); com três categorias, análise CVL/PE e existência de software para cálculo de custos, optou-se pelo teste post hoc Tukey, para identificar diferenças entre combinações.

Ao se observar as Tabelas 5 e 6, onde as diferenças significantes ao nível de 0,05 estão indicadas com * ou **, dependendo da quantidade de diferenças de uma categoria com as demais, é possível perceber que o fator relacionado à definição de preços F1 (estrutura e competição de mercado) $e$ o fator relacionado com a avaliação da empresa em comparação à concorrência F5 (produtos e/ou serviços comercializados e lançamentos), estão relacionados com a reavaliação dos padrões, o que pode significar que uma maior competitividade, atrelada a um maior número de produtos e/ou serviços no mercado e o lançamento de produtos e/ou serviços no setor de atuação da empresa pode obrigar a empresa a proceder avaliações mais frequentes em sua estrutura de custos.

Por outro lado, se o fator relacionado à definição de preços F2 (custos e margem de lucro dos produtos) está relacionado com a utilização da análise CVL/PE, pode-se dizer que quando o enfoque da empresa é formar os preços a partir dos seus custos e de uma margem de lucro, é dada maior importância a métodos como o ponto de equilíbrio (PE), utilizados para, justamente, estabelecer limites mais precisos de preços 
em estratégias de negociação específicas com clientes diferenciados ou em situações especiais.

Considerando as estratégias de preços, as empresas que possuem atividades em mercados externos tendem a discordar mais que as empresas que só trabalham no mercado interno quando o assunto é considerar o preço atrelado a produtos e/ou serviços mais simples, de menor qualidade, o que pode ser um indicador das exigências maiores dos clientes internacionais. No entanto, em relação à estratégia de pacotes de produtos e/ou serviços e itens complementares, com preços diferenciados, nota-se que empresas com menor tempo de existência, com produtos e/ou serviços com menor tempo de mercado e com menos concorrentes diretos, tendem a utilizá-la mais frequentemente do que as empresas há mais tempo no mercado, com produtos e/ou serviços mais maduros e com mais competidores frontais.

Quanto à avaliação da empresa em comparação com a concorrência, o fator F4 (mercados e clientes) apresenta médias maiores para empresas com um número de funcionários mais elevado, mais tempo de mercado, maior número de produtos, produtos com mais tempo no mercado e com existência de um manual de procedimentos para custeio. Isso é retrato da maior participação de mercado, maior número de clientes e maior formalidade no tratamento dos custos nestas empresas. Cabe reforçar que as empresas com manual de procedimentos para custeio apresentaram um número superior de produtos e/ou serviços comercializados e de lançamentos, se comparadas à concorrência.

Ao se levar em conta o setor em que as empresas atuam, o nível de sensibilidade da demanda e dos clientes ao preço, o poder de barganha de clientes e de fornecedores e o número de itens comercializados e a competição por preço, são percebidos em níveis superiores em empresas com maior número de funcionários, que, além desta percepção, também fazem mais adaptações nos produtos e/ou serviços atuais. Já a visão no que tange ao nível de custos como um todo (fixos e totais), é percebido como sendo maior nas empresas que possuem atividades no mercado internacional, que possuem produtos e/ou serviços há mais tempo no mercado e com um número menor de lançamentos, o que pode ser reflexo da taxa cambial, das exigências dos clientes no mercado externo e do nível de agressividade dos concorrentes.
Além de empresas com mais funcionários, a percepção do poder de barganha é maior em empresas com mais tempo de mercado, mais concorrentes diretos e com mais lançamentos de produtos. Empresas mais maduras e com maior concorrência sentem o peso das pressões de clientes e de fornecedores de modo mais expressivo. O maior número de itens comercializados e a competição por preços no setor também é mais visível em empresas com atividades internacionais, com maior número de concorrentes, com mais produtos e/ou serviços à venda, com produtos mais antigos no mercado e com mais lançamentos. Situação esta característica a empresas de maior porte, com mais mercados de atuação. A média desse fator, todavia, não foi estatisticamente significante para empresas com mais tempo de atuação no mercado, o que não indica que empresas mais maduras estejam sofrendo maior competição de preços e em setores com maior número de itens comercializados.

O uso de análises estatísticas para determinação de preços está relacionado à atividade em mercados externos e ao número de funcionários, o que sugere que empresas maiores e lidando com mercados mais complexos, precisam de análises mais aprofundadas. $\mathrm{O}$ uso de ferramentas estatísticas também está relacionado ao uso da análise CVL/PE e à existência de consultoria na empresa, que provavelmente sugere o emprego de inovações técnicas.

O tempo de mercado influencia a existência de um manual de custeio, mais provável em organizações mais maduras, bem como o tipo de software empregado, que teoricamente evolui com a organização, de planilhas para programas específicos. O número de concorrentes também está relacionado com a utilização da análise CVL/PE. Possivelmente, uma maior pressão competitiva force a empresa a negociações mais estreitas, onde a ferramenta CVL/PE pode ser de grande valia na determinação de preços.

Por sua vez, o número de produtos e/ou serviços da empresa está relacionado ao tipo de padrão de custos empregado, bem como à própria periodicidade da reavaliação dos padrões, devido, provavelmente, à problemática de se determinar padrões para diferentes níveis de complexidades produtivas. Além do mais, o método de custeio se relaciona com o número de lançamentos dos nos últimos dois anos, talvez pelo fato de que a inovação constante exige técnicas mais complexas de formação de preços. 


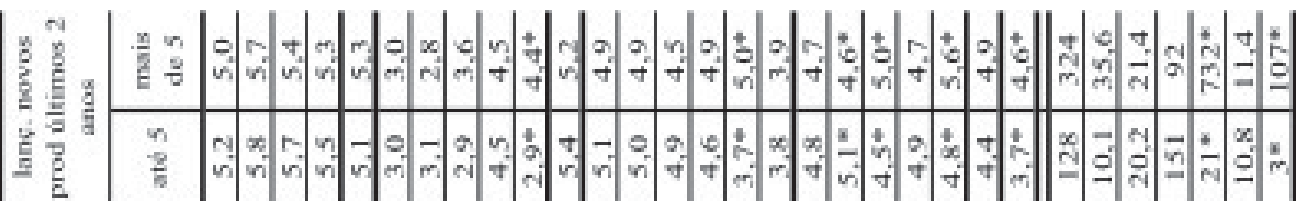

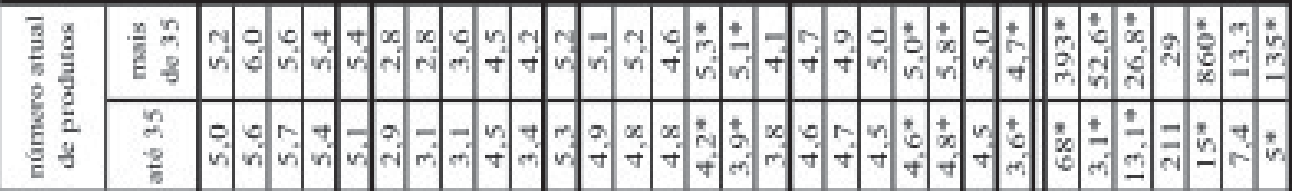

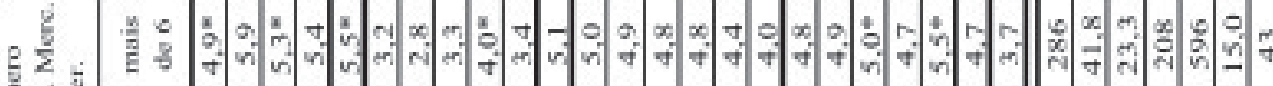

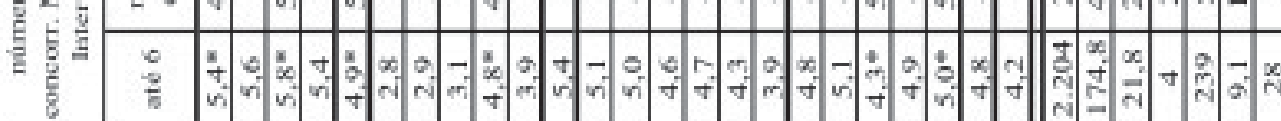

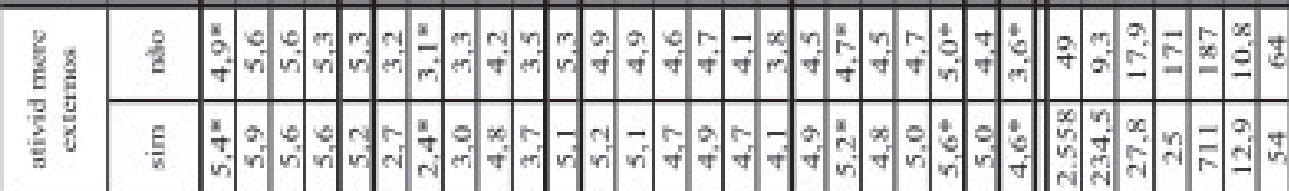

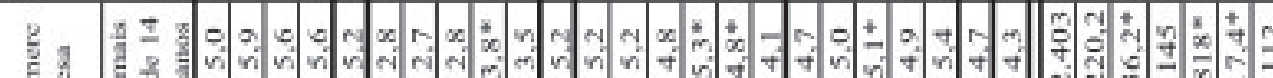

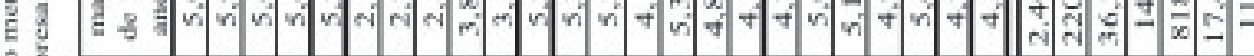

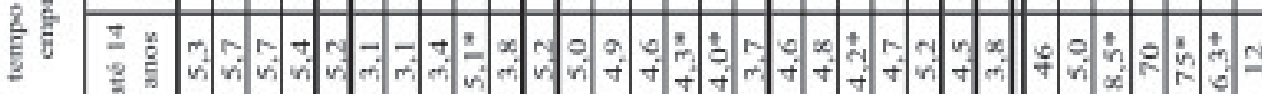

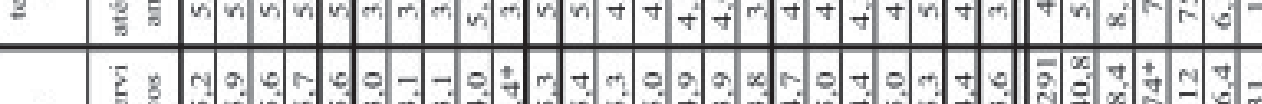

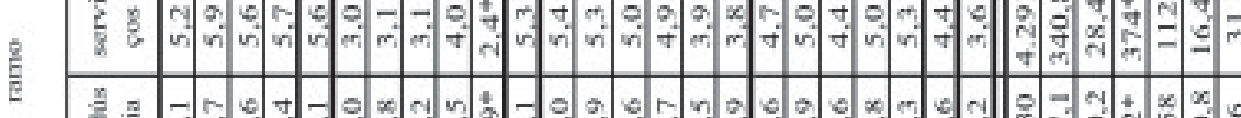

(

क के

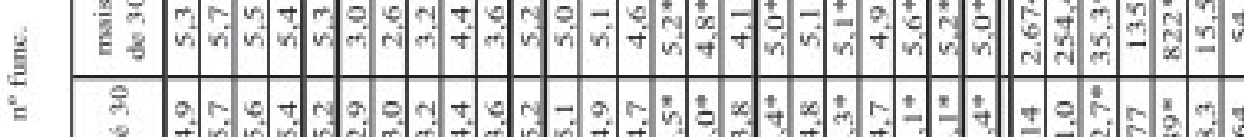

\begin{tabular}{|c|c|c|c|c|c|c|c|c|c|c|c|c|c|c|c|c|c|c|c|c|c|c|}
\hline \multirow{3}{*}{ 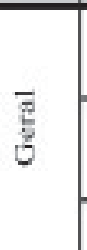 } & $\begin{array}{ll}3 \\
0 \\
0\end{array}$ & & & 7 & $a^{\circ}$ & & & $=\pi$ & & $=$ & 7 & & $\because$ & & 5 & & & $=0$ & \multicolumn{4}{|c|}{ 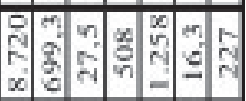 } \\
\hline & $\frac{\frac{5}{3}}{\frac{3}{2}}$ & " & & & & & & & & 담요 & & 6 & & & 7 & 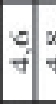 & & वी & & तู่ & : & $=0$ \\
\hline & $z$ & 汶5 & 茷 & 95 & $x$ & $x:$ & 료 & 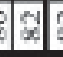 & $x$ & 可 & & & $\overline{a x}$ & $\begin{array}{c}x \\
x\end{array}$ & 2 & 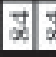 & 污 & A & 図 & $\therefore 2$ & $A 5$ & 도용 \\
\hline 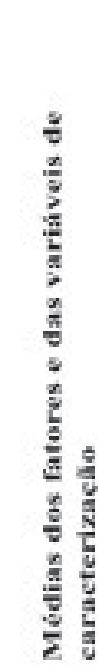 & & 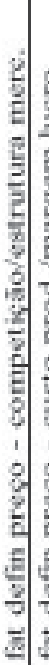 & $\frac{5}{\frac{5}{3}}$ & 倰 & 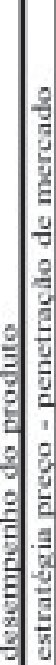 & 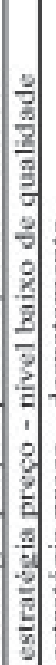 & 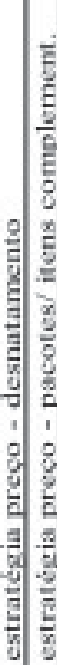 & 量 & 事 & 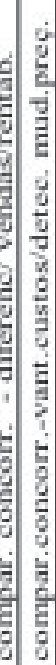 & & & 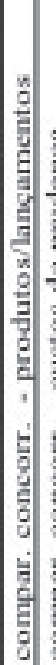 & 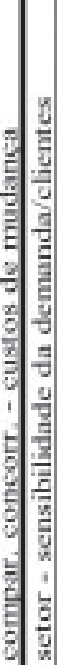 & 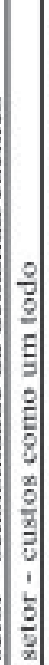 & 用 & 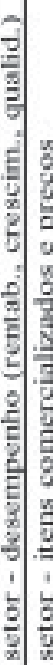 & 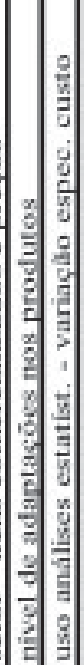 & 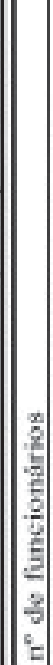 & 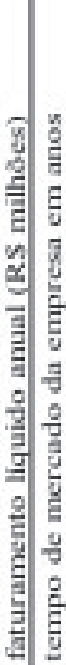 & 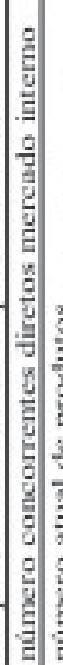 & 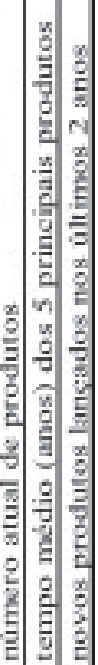 \\
\hline
\end{tabular}




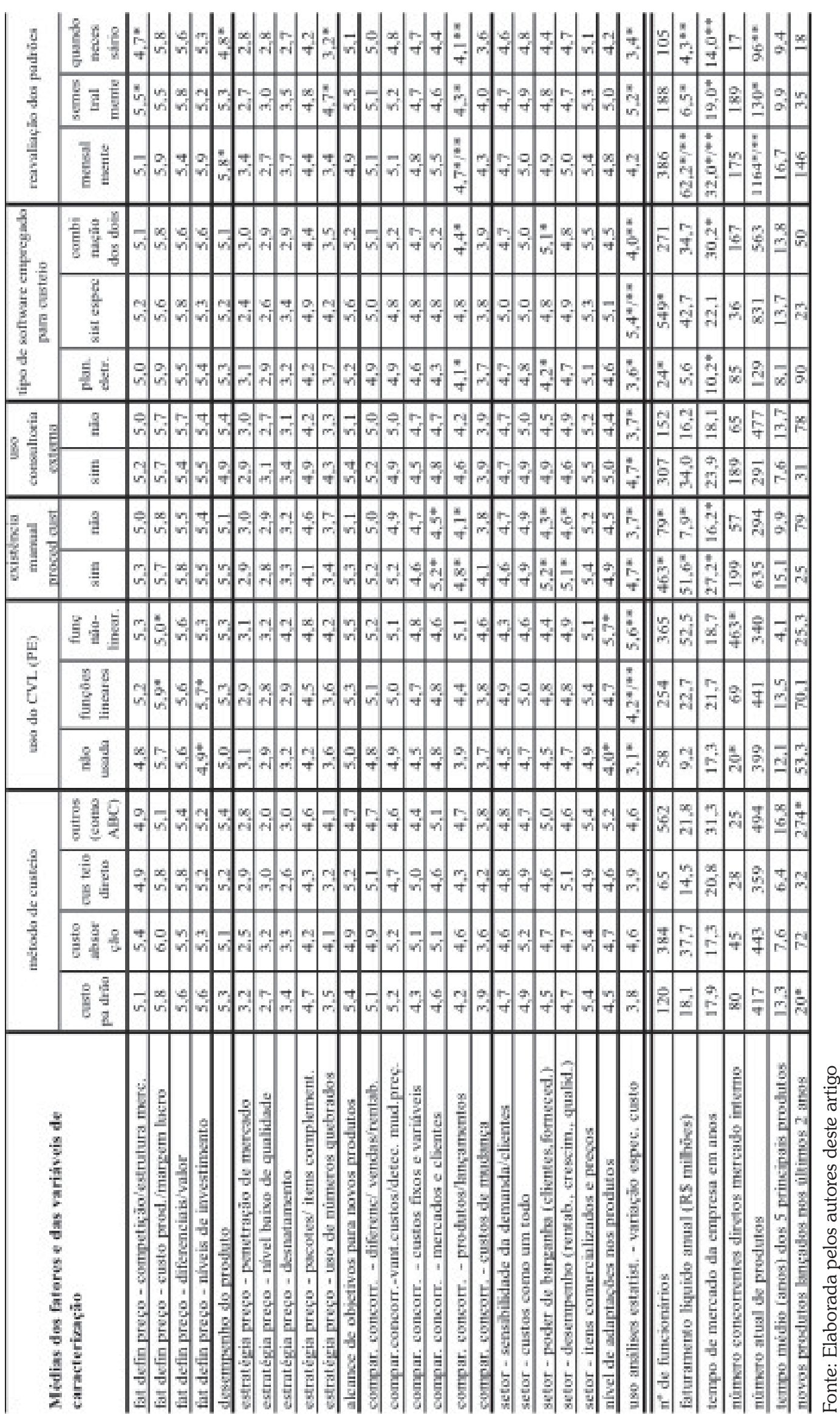


Por outro lado, percebe-se que diversos fatores apresentaram poucas médias com diferenças, estatisticamente, significantes. É o caso, principalmente, de fatores relacionados à definição de preços: F2 (custos e margem de lucro dos produtos e/ou serviços), F3 (diferenciais e valor percebido) e F4 (níveis de investimento), provavelmente em decorrência de serem dimensões básicas em relação às estratégias de precificação. A estratégia de penetração obteve médias baixas em todos os agrupamentos pesquisados, com nenhuma diferença significante, bem como a estratégia de desnatamento de mercado, diferentemente do fator de definição de preços $\mathbf{F 1}$ (estrutura e competição de mercado), onde pode ser identificada uma relação com precificação baseada na concorrência.

Quanto aos custos e à margem de lucro e à qualidade e ao valor percebido, as diferenças das médias relativas às estratégias de desnatamento e de penetração de mercado, com seus respectivos fatores, são estatisticamente significantes ao nível de 0,01 (Teste $\mathrm{t}$ em pares). Essa média baixa também ocorre com estratégias de preço equivalente a níveis baixos de qualidade e uso de preços "quebrados" (preço psicológico). Ou seja, há mais consideração de fatores relacionados a preços ligados à concorrência, ao custo e à qualidade, do que a estratégias de desnatamento ou penetração de mercado.

Também chamam atenção outros fatores que não apresentaram diferenças de médias nos grupos avaliados: alcance de objetivos para novos produtos, diferenciação, vendas e rentabilidade, vantagens em custos e na detecção de mudanças em preços, custos fixos e variáveis e custos de mudança. Esses fatores são percebidos de forma semelhante entre empresas com porte, maturidade, níveis de concorrência e ferramentas de custeio diferentes.

Em resumo, parece haver uma relação significativa entre a competitividade percebida no ambiente e a forma como o custeio é tratado na empresa, tendo em vista que mercados mais competitivos parecem exigir o uso de técnicas mais avançadas. Observa-se, ainda, um peso maior de variáveis, ou questões, relacionadas ao custo $e$ às margens de lucro e entre o binômio qualidade e valor percebido na precificação, em comparação a estratégias específicas, como, por exemplo, as estratégias de penetração ou desnatamento de mercado.
Ou seja, há emprego de técnicas avançadas em custeio sobre formas com enfoque competitivo de preços ou enfoque baseado em custo e não o enfoque de precificação para novos produtos. Além disso, o enfoque de formação de preços nos custos, e não na concorrência ou em outros parâmetros, também incentiva o uso de técnicas mais apuradas de custeio. A sofisticação destas técnicas também se relaciona com o porte, o tempo de mercado da empresa e nível de exigência dos mercados atendidos pela organização.

Finalmente, são apresentados os resultados da análise de regressão, para a qual foi utilizado o método stepwise e tratamento pairwise para dados omissos. Procurando identificar o impacto sobre as dimensões de preços no desempenho da empresa (variável dependente), foram testados diversos modelos, tendo como variáveis independentes as resultantes da Análise Fatorial (fatores de definição de preços, desempenho do produto, estratégias de precificação, alcance de objetivos para novos produtos, concorrência e setor) e a variável utilizada para avaliar as adaptações nos produtos e/ou serviços (V74).

Desses modelos, escolheu-se para análise o modelo com $\mathrm{R}^{2}$ ajustado superior a 0,50 . Neste caso, com a variável dependente relacionada à avaliação da empresa em comparação com a concorrência (F1: Diferenciação, vendas e rentabilidade), resultando em um $\mathrm{R}^{2}$ ajustado de 0,59 . Dos outros cinco modelos (as outras cinco variáveis de comparação com a concorrência), um ficou com $\mathrm{R}^{2}$ ajustado de 0,32 e os restantes abaixo de 0,30.

Assim sendo, conforme mostra a Tabela 7, o fator de maior impacto positivo na variável de desempenho é o alcance de objetivos para novos produtos, seguido de níveis de investimento, desempenho como um todo do setor, itens comercializados e preços no setor e estratégia de desnatamento de mercado. Por outro lado, a sensibilidade da demanda e dos clientes ao preço e a estratégia de preço de produtos mais simples, a menor qualidade e a estratégia de penetração causam influência negativa no desempenho do negócio, o que pode ser explicado pelas suas relações com preços mais baixos, mesmo permitindo maiores volumes de vendas. Outros fatores e estratégias de precificação, como aqueles relacionados à concorrência, qualidade e valor percebido e custos não foram significantes. Uma possível explicação é a forma como essas práticas estão 
disseminadas pelas organizações, o que pode significar carência de diferenciação em suas ofertas ao mercado.

Tabela 7: Fator de maior impacto positivo no desempenho do negócio

\begin{tabular}{|c|c|c|c|}
\hline FATORES & $\begin{array}{c}\text { Coeficiente } \\
\text { Padronizado } \\
\text { (Beta) }\end{array}$ & $\begin{array}{l}\text { VALOR } \\
\text { TOTAL }\end{array}$ & $\begin{array}{l}\text { SignifI- } \\
\text { CÂNCIA }\end{array}$ \\
\hline $\begin{array}{l}\text { Alcance de objetivos } \\
\text { para novos produtos e/ } \\
\text { ou serviços }\end{array}$ & 0,31 & 3,66 & 0,00 \\
\hline Níveis de investimento & 0,30 & 3,92 & 0,00 \\
\hline $\begin{array}{l}\text { Desempenho do } \\
\text { setor como um todo } \\
\text { (crescimento, qualidade } \\
\text { de produtos e/ou } \\
\text { de serviços, lucro e } \\
\text { rentabilidade) }\end{array}$ & 0,29 & 3,74 & 0,00 \\
\hline $\begin{array}{l}\text { Itens comercializados e } \\
\text { preços praticados }\end{array}$ & 0,19 & 2,46 & 0,02 \\
\hline $\begin{array}{l}\text { Estratégia de } \\
\text { desnatamento de } \\
\text { mercado }\end{array}$ & 0,19 & 2,46 & 0,02 \\
\hline $\begin{array}{l}\text { Estratégia de penetração } \\
\text { de mercado }\end{array}$ & $-0,21$ & $-2,24$ & 0,03 \\
\hline $\begin{array}{l}\text { Sensibilidade da } \\
\text { demanda e dos clientes } \\
\text { ao preço }\end{array}$ & $-0,24$ & $-2,70$ & 0,01 \\
\hline $\begin{array}{l}\text { Produtos mais simples, } \\
\text { com qualidade de nível } \\
\text { baixo ou intermediário }\end{array}$ & $-0,25$ & $-3,14$ & 0,00 \\
\hline
\end{tabular}

Fonte: Elaborada pelos autores deste artigo

\section{Considerações Finais}

Os gestores devem entender o contexto da precificação, incluindo o contexto mercadológico em que a empresa está inserida e, principalmente, a percepção de valor do consumidor, relação esta que compara benefícios almejados e sacrifícios incorridos, mas, também, compreender a importância do preço praticado no mercado, estrategicamente definido, e sua influência na performance do negócio. De maneira complementar, é fundamental que os gestores verifiquem as interfaces e as implicações dos métodos e sistemas de aferição dos custos no que diz respeito à estratégia de precificação adotada pela empresa.
Dessa forma, integrar áreas funcionais como as áreas de marketing e de finanças e controladoria no que se refere a uma melhor compreensão sobre o mercado de atuação da empresa, é cada vez mais premente. Por meio de uma maior sinergia entre as áreas funcionais, as empresas podem ampliar o desempenho organizacional perante a concorrência, permitindo, um melhor posicionamento mercadológico e o estabelecimento e a consolidação de uma vantagem competitiva sustentável. (PORTER, 1985; HOOLEY; SAUDERS; PIERCY, 2005)

Para tanto, para um gerenciamento pró-ativo dos preços, e que gere repercussões positivas para as empresas, alguns passos são imprescindíveis, ou seja: (i) pesquisar o ambiente em que o preço será praticado para entender os fatores que influenciam a dinâmica da oferta e da demanda; (ii) estabelecer a estratégia de precificação adequada ao posicionamento de mercado desejado; e (iii) implementar as ações necessárias à política de preços pré-estabelecida pela empresa. (MONROE; COX, 2001)

Portanto, a partir dos achados provenientes da presente pesquisa, é possível ilustrar que os gestores devem prestar mais atenção entre a relação existente entre os processos de definição das estratégias de preço (precificação) e os sistemas de custeio adotados, o que, em última instância, devem estar direcionados à possibilidade de gerar melhores resultados, tanto atinentes à dimensão mercadológica quanto à dimensão relativa à performance econômico-financeira das empresas.

\section{REFERÊNCIAS}

BERNARDI, L. A. Política e formação de preços: uma abordagem competitiva, sistêmica e integrada. São Paulo: Atlas, 1996.

\section{COGAN, S. Custos e preços: formação e análise.} São Paulo: Pioneira Thomson Learning, 2002.

CRESSMAN Jr., G. S. Commentary on: industrial pricing: theory and managerial practice. Marketing Science, Catonsville, v. 18, n. 3, p. 455-457, 1999.

DIAMANTOPOULOS, A. Determinação de preços. In: BAKER, M. (Org.) Administração de marketing. Rio de Janeiro: Elsevier, 2005. 
DOLAN, R. J.; SIMON, H. O poder dos preços: as melhores estratégias para ter lucro. São Paulo: Futura, 1998.

GOURVILLE, J. T.; SOMAN, D. Pricing and the psychology of consumption. Harvard Business Review, Boston, v. 80, n. 9, p. 90-96, 2002.

GUILTINAN, J. P.; GUNDLACH, G. T. Aggressive and predatory pricing: a framework for analysis. Journal of Marketing, Chicago, v. 60, n. 3, p. 87-102, 1996.

HAIR Jr., J. F. et al. Multivariate data analysis. $5^{\text {th }}$ edition. Upper Saddle River: Prentice Hall, 1998.

HAIR Jr., J. F; BUSH, R. P.; ORTINAU, D. J. Marketing research: a practical approach for the new millennium. New York: Irwin/McGraw-Hill, 2000.

HEIL, O. P.; HELSEN, K. Toward an understanding of price wars: their nature and how to they erupt. International Journal of Research in Marketing, Netherlands, v. 18, n. 1/2, p. 83-98, 2001.

HOOLEY, G. J.; SAUNDERS, J. A.; PIERCY, N. F.

\section{Estratégia de marketing e posicionamento} competitivo. 3. ed. São Paulo: Prentice Hall, 2005.

INGENBLEEK, P., DEBRUYNE, M., FRAMBACK, R., VERHALLEN, T. Successful new product pricing practices: a contingency approach. Marketing Letters, London, v. 14, n. 4, p. 289-305, Dec. 2003.

JOHNSON, R. A.; WICHERN, D. W. Applied multivariate statistical analysis. $5^{\text {th }}$ edition. International Edition: Prentice Hall, 2002.

KOTLER, P.; KELLER, K. L. Administração de marketing. 12. ed. São Paulo: Prentice Hall, 2006.

KRISHNAMURTHI, L. Pricing: part art, part science. Mastering Marketing. Financial Times/Prentice Hall, 1999.

MACHADO, M. et al. Análise do processo de formação de preços do setor hoteleiro da cidade de João Pessoa (PB): um estudo exploratório. In: Encontro Anual da Anpad, 30. Anais... Salvador: ANPAD, 2006.

MALHOTRA, N. Pesquisa de marketing: uma orientação aplicada. 4. ed. Porto Alegre: Bookman, 2006.
McDONALD, M. Planos de marketing: planejamento e gestão estratégica. Rio de Janeiro: Elsevier, 2004.

MONROE, K. B.; COX, J. L. Pricing practices that endanger profits. Marketing Management, London, v. 10, n. 3, p. 42-46, Sep.-Oct. 2001.

\section{NAGLE, T.; HOLDEN, R. K. Estratégias e táticas de} preços: um guia para as decisões lucrativas. São Paulo: Prentice Hall, 2003.

NASCIMENTO NETO, R.; MIRANDA, L. Utilização de sistemas de custeio em indústrias brasileiras: uma pesquisa empírica. In: Encontro Anual da Anpad, 27. Anais... Atibaia: ANPAD, 2003.

NICHELE, M.; MILAN, G. S. Fundamentos, estratégias e decisões de preço. In: MILAN, G. S.; BRANCHI, V. L. (Org.) Administração mercadológica: teoria $e$ pesquisas. Volume 2. Caxias do Sul: EDUCS, 2006. (Cap. 7, p. 151-180)

NOBLE, P. M.; GRUCA, T. S. Industrial pricing: theory and managerial practice. Marketing Science, Catonsville, v. 18, n. 3, p. 435-454, 1999.

PORTER, M. E. Competitive advantage. New York: The Free Press, 1985.

RAO, A. R.; BERGEN, M. E.; DAVIS, S. How to fight a price war. Harvard Business Review, Boston, v. 78, n. 2, p. 107-116, 2000.

RAMOS, P. M.; MAYA, P. C. C.; BORNIA, A. C. Estudo científico do componente preço e sua relação com o marketing mix de produto brasileiro de exportação: uma pesquisa multicasos nas empresas do consórcio de exportação de calçados de São João Batista (SC). In: Encontro Anual da Anpad, 29. Anais... Brasília: ANPAD, 2005.

SIMON, H. Pricing opportunities and how to exploit them. Sloan Management Review, Massachusetts, v. 33, n. 2, p. 55-65, 1992.

SOUZA, A. et al. Análise de sistemas de informações utilizados como suporte para os processos de estimação de custos e formação de preços. In: Encontro Anual da Anpad, 29. Anais... Brasília: ANPAD, 2005. 
. O processo de formação de preços em empresas de produção por encomenda: estudo de casos múltiplos na região metropolitana de Belo Horizonte. In: Encontro de Marketing, 1. Anais... Rio de Janeiro: ANPAD, 2006.

TORRES, U. P. P; MARTINS, H. C. Análise estratégica das áreas de marketing e finanças no processo de formação e manutenção dos preços: o caso da montadora Fiat Automóveis S.A. In: Encontro de Marketing, 1. Anais... Rio de Janeiro: ANPAD, 2006.

URBANY, J. E. Determinação e estratégias de definição de preços. In: CZINKOTA, M. et al. Marketing: as melhores práticas. Porto Alegre: Bookman, 2001.

URDAN, A.; OSAKU, W. Determinantes do sucesso de novos produtos: um estudo de empresas estrangeiras no Brasil. In: Encontro Anual da Anpad, 29. Anais... Brasília: ANPAD, 2005.

VIEIRA, J.; ROBLES JÚNIOR, A. O custeio baseado em atividades $(A B C)$ e a gestão por atividades ( $A B M)$ no ambiente das empresas de autopeças do Estado de São Paulo. In: Encontro Anual da Anpad, 26. Anais... Salvador: ANPAD, 2002.

WYNER, G. A. New pricing realities. Marketing

Research, EUA, v. 13, n. 1, p. 34-35, 2001.

\section{Anexo A - Variáveis Utilizadas na Pesquisa}

\section{Variáveis Utilizadas na Pesquisa}

1. As vantagens que o produto oferece ao consumidor.

2. O equilibrio entre as vantagens do produto e o possível preço.

3. As vantagens que o produto oferece em comparação aos produtos dos concorrentes.

4. O valor percebido do produto pelos clientes (benefícios versus custos).

5. As vantagens do produto comparadas com outros substitutos.

6. O preço dos produtos dos concorrentes.

7. O grau de competição no mercado.

8. Os sistemas de vendas, promoção e distribuição dos concorrentes.

9. A atual estratégia de preço dos concorrentes.

10. A estrutura do mercado (o número de concorrentes, suas ações, estruturas e forças).

11. As reações dos concorrentes aos nossos preços.

12. A capacidade dos concorrentes para mudanças rápidas de preços.

13. As vantagens competitivas dos concorrentes no mercado.

14. A participação dos custos fixos no custo total.

15. O custo total do produto.

16. Os custos variáveis do produto.

17. A margem percentual de lucro sobre o preço, definida pela empresa.

18. O valor necessário para que se atinja o ponto de equilibrio.

19. Os investimentos no novo produto.

20. O produto ofereceu qualidade maior em relação aos concorrentes.

21. O produto solucionou problemas que os clientes tinham com produtos concorrentes.

22. O produto foi bastante inovador e serviu como substituto a outros produtos já existentes.

23. O produto solucionou problemas que os clientes tinham com produtos concorrentes.

24. Nós definimos o preço inicialmente alto e, então, sistematicamente, nós o reduzimos com o tempo.

25. Nossos clientes esperam que o preço caia com o tempo.

26. Nós inicialmente definimos o preço baixo para acelerar a adoção do produto. 
27. Nós definimos o preço baixo para alavancar o volume de vendas e reduzir custos através da experiência acumulada.

28. Nós sempre procuramos ter um preço baixo no mercado, em relação aos concorrentes.

29. Oferecemos produtos a um preço maior em nossos segmentos de mercado mais importantes e a um preço menor, por meio de descontos, em segmentos de mercado menos importantes.

30. Oferecemos descontos de forma sistemática e previsível.

31. Oferecemos descontos ocasionalmente e de forma imprevisível.

32. Definimos os preços com base no que os consumidores possuem em mente como referência.

33. Nossos preços possuem números quebrados ou terminam em números ímpares.

34. Nossos clientes observam os preços de nossos produtos como indicadores de alta qualidade.

35. Para os produtos que possuem itens complementares, ou opcionais (tais como acessórios, partes, peças e serviços), colocamos uma margem de lucro menor no produto básico/central e margens de lucros maiores nos itens complementares (preço premium).

36. Nossos preços estão em nível intermediário no mercado em função da qualidade intermediária de nossos produtos, em relação aos concorrentes.

37. Nós oferecemos produtos a preços competitivos, mas em uma versão mais simples, com menos características (opções), se comparadas às outras versões.

38. Nossos preços são baixos no mercado em função da qualidade inferior de nossos produtos, em relação à concorrência.

39. Nossos preços são elevados em função da alta qualidade de nossos produtos, em relação à concorrência.

40. Nós oferecemos pacotes de produtos (um conjunto de vários produtos), em um preço total que permite aos clientes boas economias se considerassem os produtos comprados individualmente.

41. Objetivos de vendas desde que foi lançado.

42. Objetivos de participação de mercado desde o lançamento.

43. Margens de lucro esperadas desde o lançamento.

44. Vantagem de custos devido à curva de experiência.

45. Vantagem de custos devido às economias de escala.

46. Participação de mercado (em relação ao líder de mercado).

47. Utilização relativa da capacidade instalada.

48. Diferenciação dos produtos, de forma geral.

49. Custos totais.

50. Custos fixos.
51. Número de clientes ativos (considerando os últimos 12 meses).

52. Preços dos produtos, de forma geral.

53. Crescimento médio nas vendas.

54. Capacidade em detectar mudanças de preços.

55. Rentabilidade média dos produtos básicos (ou dos produtos comercializados, para os que não trabalham com produtos e/ou serviços complementares).

56. Rentabilidade média das vendas dos produtos/serviços suplementares (acessórios e opcionais), caso existam.

57. Custos de mudança (custos ou dificuldades para mudar para o produto de outro concorrente).

58. Número de itens de produtos comercializados.

59. Número médio de anos no mercado dos principais produtos comercializados.

60. Número de lançamentos de novos produtos.

61. Crescimento do mercado como um todo.

62. Taxa de concentração das três maiores empresas do mercado.

63. Competição de preços.

64. Sensibilidade dos clientes às diferenças de preço entre marcas.

65. Sensibilidade da demanda total às mudanças no preço médio.

66. Qualidade dos produtos como um todo.

67. Custos totais do setor como um todo.

68. Custos fixos do setor como um todo.

69. Rentabilidade média do setor.

70. Número de barreiras aos novos entrantes.

71. Poder de barganha dos clientes no setor como um todo.

72. Poder de barganha dos fornecedores no setor como um todo.

73. Número de itens de produtos comercializados.

74. Considerando os novos produtos lançados nos últimos dois anos, de forma geral, como você avalia o seu grau de inovação? (1 como sendo poucas adaptações em produtos já existentes e 7 como sendo totalmente um novo produto)? 